\title{
ПЕРЕНОС ЭНЕРГИИ ЭЛЕКТРОННОГО ВОЗБУЖДЕНИЯ С УЧАСТИЕМ МОЛЕКУЛ ХЛОРОФИЛЛА И ЕГО ПРОИЗВОДНЫХ
}

Перенос энергии (ПЭ) электронного возбуждения и локализация ее на реакционных центрах фотосинтетических единиц является одной из основных проблем в изучении первичных фотофизических процессов in vivo. Высокая локальная концентрация хлорофилла и сопровождающих пигментов в растениях, особенности спектрально-люминесцентных характеристик и физико-химических свойств пигментов приводят $\mathrm{K}$ весьма высокой эффективности ПЭ в фотосинтетическом аппарате. В этом отношении систематическое изучение безызлучательного переноса фотовозбуждения с участием молекул основных фотосинтетических пигментов в модельных системах с постепенным их усложнением представляет не только самостоятельный интерес, но и является необходимым этапом в исследовании первичных фотофизических процессов непосредственно in vivo $\left[{ }^{1-4}\right]$.

В данном сообщении приводятся результаты всестороннего исследования закономерностей и механизмов различных типов ПЭ, осуществляющихся как по синглетным, так и по триплетным уровням хлорофилла и его аналогов в различных состояниях (от истинных молекулярных растворов до агрегированных систем).

Наиболее полно исследован в ряде работ ПЭ, происходящий по синглетным уровням мономерных молекул пигментов:

$$
{ }^{1} D^{*}+{ }^{1} A \rightarrow{ }^{1} D+{ }^{1} A^{*} .
$$

Гомогенная миграция такого типа в растворах хлорофилла и его аналогов приводит к деполяризации люминесценции $\left[{ }^{4-7}\right]$, концентрационному уменьшению квантовых выходов свечения и интеркомбинационной конверсии $\left[{ }^{8,9}\right]$, а также к сокращению среднего времени жизни возбужденного состояния $\left[{ }^{4}\right]$ (см. рис. 1$)$. Сопоставление результатов по концентрационной деполяризации люминесценции пигментов в изотропных растворах касторового масла $\left[{ }^{4,5}\right]$, в гетерогенных мицеллярных системах $\left[{ }^{7}\right]$ и в ориентированных пленках поливинилбутираля $\left[{ }^{10}\right]$ с расчетами по современным теориям этого явления $\left[{ }^{11,12}\right]$ однозначно показывает, что в широкой области концентраций $\left(1 \cdot 10^{-5}-\right.$ $\left.-1 \cdot 10^{-1} M\right)$, захватывающей и локальную концентрацию хлорофилла in vivo $\left(5 \cdot 10^{-2}-1 \cdot 10^{-1} M\left[{ }^{5}\right]\right)$, миграция возбуждения по синглетным уровням мономерных молекул обусловлена индуктивно-резонансным механизмом Ферстера-Галанина $\left[{ }^{13,14}\right]$. Кроме того, нами установлено, что гетерогенный ПЭ между мономерными молекулами отличающихся друг от друга пигментов происходит без квантовых потерь и полностью описывается механизмом индуктивного резонанса $\left[{ }^{15}\right]$. Полученные данные в сопоставлении с результатами аналогичного исследования спектрально-люминесцентных свойств хлорофилла в фотосинтетическом аппарате растений позволяют заключить, что процесс миграции энергии по 

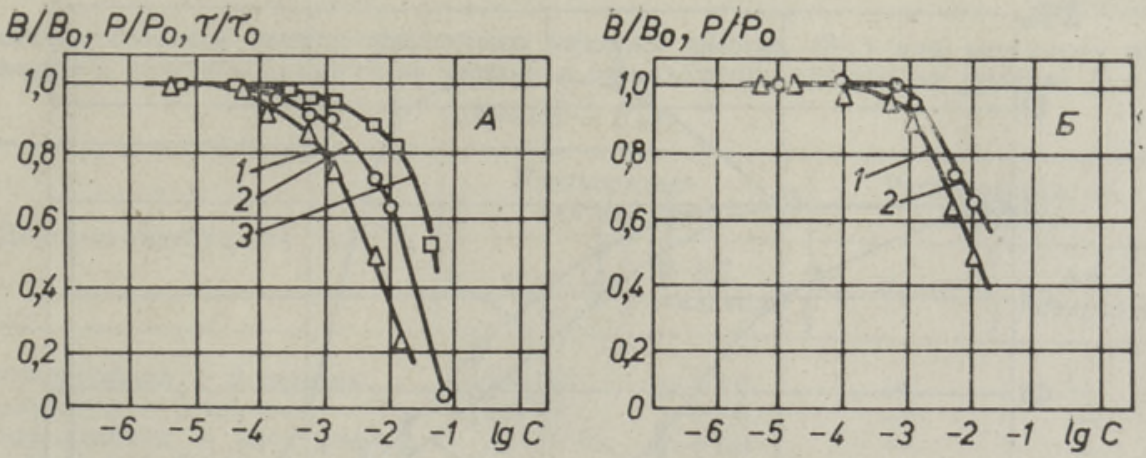

\section{$P / P_{0}, B / B_{0}$}
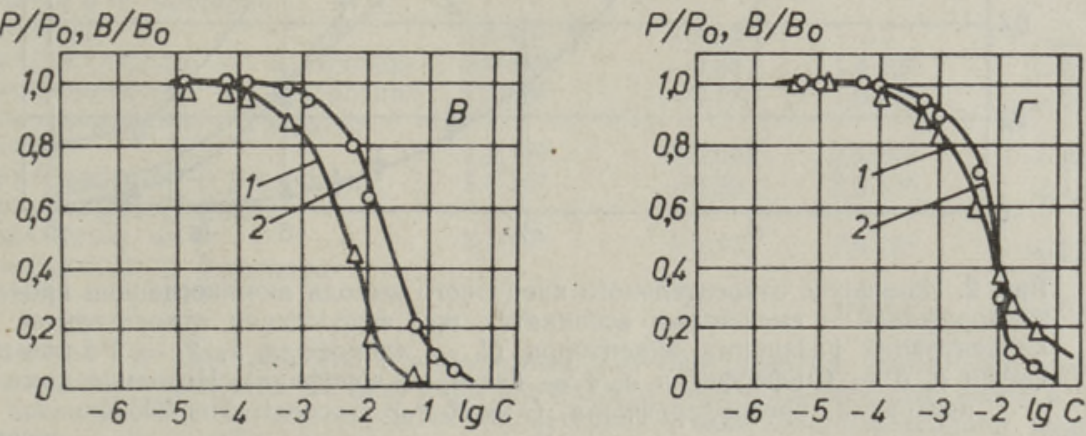

Рис. 1. Падение степени поляризации $P / P_{0}(1)$, квантового выхода $B / B_{0}$ (2) и времени жизни возбужденного состояния $\tau / \tau_{0}(3)$ люминесценции хлорофилла $a$ (А), хлорофилла $b$ (Б), феофитина $a$ (В) и 4-винил-протохлорофилла (Г) в касторовом масле с ростом конщентрации, $T=293 \mathrm{~K}$.

антенному хлорофиллу фотосистемы II зеленых растений описывается теорией индуктивного резонанса.

ПЭ по синглетным уровням взаимодействующих молекул, обусловленный более сильными взаимодействиями, чем индуктивно-резонансное, удается обнаружить и исследовать в смешанных ассоциатах пигментов. В экспериментах с водно-диоксановыми растворами хлорофилла и его аналогов, где создаются благоприятные условия для образования смешанных упорядоченных по структуре олигомерных комплексов с переменным соотношением донорной и акцепторной компонент, наблюдается эффективный внутрикомплексный ПЭ электронного возбуждения даже в тех случаях, когда интеграл перекрывания спектров люминесценции донора и поглощения акцептора мал (протохлорофилл - бактериохлорофилл) или донор обладает слабой флуоресцентной способностью (неоксантин-протохлорофилл) $\left[{ }^{16-18}\right]$ (см. рис. 2). Оценка энергии взаимодействия $V_{12}$ молекул в совместном комплексе приводит к величинам $10 \mathrm{~cm}^{-1} \leqslant V_{12} \leqslant 75 \mathrm{~cm}^{-1}$, т. е. нижний предел вероятности ПЭ в таких системах может достигать $F \simeq 10^{12} c^{-1}$. Следовательно, вероятность миграции возбуждения в смешанных ассоциатах пигментов оказывается сравнимой с вероятностью колебательной релаксации в сложных органических молекулах $\left(W \simeq 10^{12}-10^{13} c^{-1}\right)$. Подтверждает это обнаружение предрелаксационного обратного ПЭ в смешанных ассоциатах типа протохлорофилл-хлорофилл $a$ и протохлорофилл-Pd-феофитин $a \cdot\left[{ }^{19}\right]$. Такой обратный ПЭ должен происходить в процессе установления больцмановского распределения по колебательным подуровням возбужденного состояния акцептора. В этом случае механизм переноса обусловлен межмолекулярным взаимодействием, относящимся по критерию Ферстера к области между колеба- 


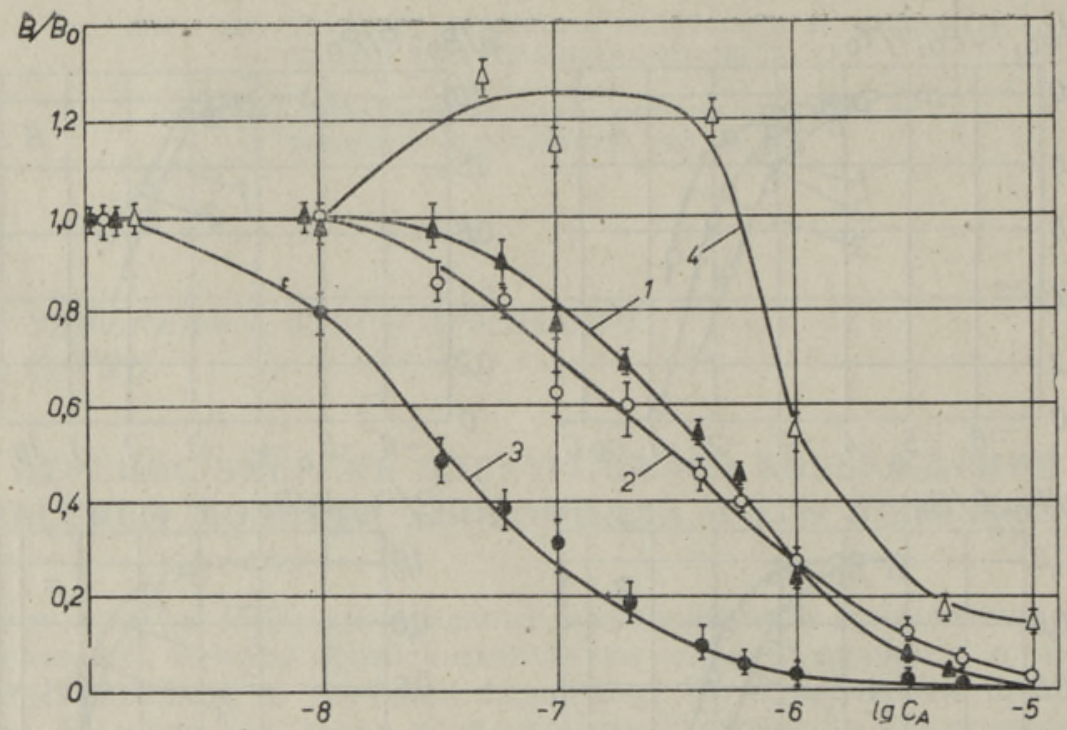

Рис. 2. Изменение относительного квантового выхода люминесценции протохлорофилла в смешанных ассоциатах при возрастании относительной концентрации различных акцепторов $(1-$ хлорофилл $a, 2-\mathrm{Pd}-\phi е о-$ фитин $a, 3$ - Сu-феофитин $a, 4$ - бактериохлорофилл). Исходная концентрация протохлорофилла $C=10^{-5} M=$ const, $T=293 \mathrm{~K}$.

тельно-релаксационным резонансным переносом и случаем «локализованного экситона». Рассматриваемые системы представляют собой промежуточное звено между молекулярными кристаллами и растворами. Однако, к сожалению, общей и строгой теории такого рода взаимодействий в ассоциированных системах нет и это является серьезным препятствием для полной интерпретации всей совокупности экспериментальных фактов. Тем не менее рассматриваемые системы являются хорошей моделью фотосинтетических единиц мультицентрального типа и позволяют более определенно анализировать взаимосвязь между скоростью миграции возбуждения в окрестности реакционного центра и вероятностью захвата энергии в самом реакционном центре, т. е. со скоростью первичного фотохимического разделения зарядов.

Несомненный интерес представляет ПЭ по триплетным уровням пигментов in vivo, поскольку триплетные состояния хлорофилла имеют относительно большое время жизни по сравнению с синглетными состояниями и легко участвуют в лимитируемых диффузией химических реакциях. Кроме того, в последнее время обнаружено триплетное состояние каротиноидов и хлорофилла в растениях $\left[{ }^{20}\right]$ и бактериохлорофилла в фотосинтезирующих бактериях $\left[{ }^{21}\right]$. Триплет-триплетный ПЭ от донора (Д) к акцептору (А) может быть представлен в виде следующей схемы:

$$
{ }^{3} D^{*}+{ }^{1} A \rightarrow{ }^{1} D+{ }^{3} A^{*} .
$$

В разбавленных растворах пигментов $\left(C \simeq 10^{-5}-10^{-6} \mathrm{M}\right)$ с помощью метода импульсного фотолиза нами обнаружено сокращение времени жизни триплетных состояний Д и возрастание амплитуды сигнала T-Т-поглощения у А. Понижение температуры растворов до 193 К приводило к полному исчезновению наблюдаемых эффектов, т. е. в обнаруженном T-T-переносе определящую роль играет диффузия молекул. Процесс тушения триплетных состояний Д подчиняется зависимости Штерна-Фольмера. Константа переноса, определяемая из этой зависи- 
Константы скорости триплет-триплетного переноса энергии $\left(K_{n}\right)$ для различных пар пигментов и величины разности по энергии в расположении триплетных уровней Д и А $\left(\Delta E=E_{D}^{T}-E_{A}^{T}\right)$.

\begin{tabular}{|c|c|c|c|c|}
\hline \multirow{2}{*}{ Донорно-акцепторная пара } & \multicolumn{2}{|c|}{$\begin{array}{c}\text { Растворитель - } \\
\text { диэтил. эфир }\end{array}$} & \multicolumn{2}{|c|}{$\begin{array}{c}\text { Растворитель } \\
\text { пиридин }\end{array}$} \\
\hline & $K_{\mathrm{n}}, M^{-1} \cdot c^{-1}$ & 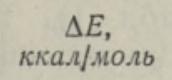 & $K_{\text {In }}, M^{-1} \cdot c^{-1}$ & $\underset{\kappa \kappa a \Omega / \text { молt }}{\Delta E}$ \\
\hline $\begin{array}{l}\text { Протохлорофилл }+\beta \text {-каротин } \\
\text { Хлорофилл } a+\beta \text {-каротин } \\
\text { Протохлорофнлл }+ \text { хлорофилл } a \\
\text { Хлорофнлл } a+\text { бактерио- } \\
\text { хлорофилл } \\
\text { Бактериохлорофилл }+\alpha \text {-каротин } \\
\text { Бактериохлорофилл }+\beta \text {-каротин } \\
\text { Бактериохлорофилл }+ \text { спирилл- } \\
\text { оксантин } \\
\text { Бактериофеофитин }+\beta \text {-каротин } \\
\text { Бактернофеофитин }+ \text { спи- } \\
\text { риллоксантин } \\
\text { Zп-фталоцианин }+\beta \text {-дигидро- } \\
\text { каротин }\end{array}$ & $\begin{array}{l}2,8 \cdot 10^{9} \\
2,8 \cdot 10^{9} \\
2,7 \cdot 10^{9} \\
1,8 \cdot 10^{9} \\
8,0 \cdot 10^{8} \\
1,1 \cdot 10^{9} \\
1,4 \cdot 10^{9} \\
1,8 \cdot 10^{9} \\
2,1 \cdot 10^{9} \\
-\end{array}$ & $\begin{array}{l}>+3,0 \\
>+3,0 \\
+3,0 \\
+1,03 \\
-0,44 \\
-0,18 \\
+0,007 \\
+0,39 \\
+0,72 \\
-\end{array}$ & $\begin{array}{l}\overline{-} \\
\overline{1} \overline{4} \cdot 10^{8} \\
1,9 \cdot 10^{8} \\
2,6 \cdot 10^{8} \\
6,0 \cdot 10^{8} \\
7,0 \cdot 10^{8} \\
4,6 \cdot 10^{8}\end{array}$ & $\begin{array}{l}\overline{-} \\
\overline{-} \\
-0,77 \\
-0,55 \\
+1,28 \\
+2,0 \\
+0,43\end{array}$ \\
\hline
\end{tabular}

Примеч ание. Для получения абсолютных значений энергии триплетных уровней была определена величина $\Delta E$ для пары $\mathrm{Zn}$-фталоцианин $+\beta$-дигидрокаротин в пиридине, поскольку положение нижнего триплетного уровня Zn-фталоцианина надежно

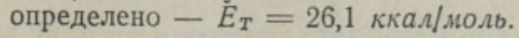

Таблица 2

Спектрально-люминесцентные характеристики и параметры переноса с участием возбужденных триплетных состояний акцептора

\begin{tabular}{|c|c|c|c|c|c|c|c|c|}
\hline \multicolumn{2}{|c|}{ Концёнтрации } & \multirow{2}{*}{$\begin{array}{c}\text { Исход- } \\
\text { ный } \\
\text { кванто- } \\
\text { вый вы- } \\
\text { ход све- } \\
\text { чения } \\
\text { донора } \\
B_{0}\end{array}$} & \multirow{2}{*}{$\begin{array}{c}\text { Показат. } \\
\text { преломл. } \\
\text { раст-ля } \\
n\end{array}$} & \multirow{2}{*}{$\begin{array}{c}\text { Интеграл } \\
\text { перекрытия } \\
\int_{0}^{\infty} f_{D}(v) \varepsilon_{A}^{T}(v) \\
X d v / v^{4} \\
c M^{6} / \text { моль }\end{array}$} & \multicolumn{2}{|c|}{$\begin{array}{c}\text { Критическое } \\
\text { расстояние } \\
\text { переноса } R_{0}, \AA\end{array}$} & \multicolumn{2}{|c|}{$\begin{array}{c}\text { Сокращение } \\
\text { времени } \\
\text { жизни воз- } \\
\text { бужденных } \\
\text { молекул } \tau / \tau_{0}\end{array}$} \\
\hline$C_{M} C_{M}^{s}$ & $\underset{M}{C_{A}^{T}}$, & & & & теop. & эксп. & теop. & эксп. \\
\hline
\end{tabular}

1. Синглет-триплет-триплетный перенос

Пирен (Д) + Mg-фталоцианин (А) в поливинилбутирале, $T=293 \mathrm{~K}$
$1 \cdot 10^{-2}\left|2,3 \cdot 10^{-3}\right|$
0,72
1,489
$5,2 \cdot 10^{-14} \mid 40$
$40 \mid 0,76$
0,71

2. Триплет-триплет-триплетный перенос

Бензофенон (Д) + Mg-мезопорфирин (А) в этаноле, $T=77 \mathrm{~K}$
$1,5 \cdot 10^{-2}\left|3,2 \cdot 10^{-3}\right|$
0,74
1,362
$2,1 \cdot 10^{-13}$
55
$57|0,44| 0,40$

При ме ч а ия. 1. Время жизни флуоресценции пирена в отсутствие переноса $\tau_{0}=$ $=3,8 \cdot 10^{-7} \mathrm{c}$.

2. Время жизни триплетного состояния $\mathrm{Mg}$-фталоцианина $\tau_{T}=$ $=1 \cdot 10^{-5} \mathrm{c}$.

3. Время жизни фосфоресценции бензофенона в отсутствие переноса $\tau_{0}=5,3 \cdot 10^{-3} c$.

4. Время жизни триплетного состояния $\mathrm{Mg}$-мезопорфирина $\tau_{T}=$ $=1,1 \cdot 10^{-1} \mathrm{c}$.

мости, в описываемых условиях зависит от энергетического зазора между положениями триплетных уровней Д и А, от природы растворителя, изменяющего состояние сольватации молекул хлорофилла $a$, и 
мо̆жѐт достигать величин $\sim 3 \cdot 10^{9} M^{-1} c^{-1}\left[{ }^{22}\right]$. Совокупность полученных данных позволяет заключить, что обнаруженный ПЭ носит обменно-резонансный характер и разрешен спиновыми правилами отбора $\left[{ }^{23}\right]$. На основании проведенных исследований были определены положения триплетных уровней ряда пигментов (бактериальные пигменты и каротиноиды) с низкими квантовыми выходами фосфоресценции $\left(\sim 10^{-5}\right)$ и коротким временем жизни триплетных состояний $\left(10^{-4}-10^{-6}\right.$ c) (см. табл. 1). Представленные результаты позволяют более определенно конкретизировать механизм защитного действия каротиноидов в процессе фотосинтеза и вместе с тем показывают, что для люминесцирующей формы хлорофилла in vivo вклад Т-T-переноса незначителен по сравнению с вкладом эффективного синглет-синглетного переноса.

Как известно $\left[{ }^{13,14}\right]$, эффективность миграции за счет кулоновских взаимодействий между молекулами Д и А существенным образом зависит от разрешенности в дипольном приближении электронных переходов в молекулах А. Поэтому теоретически возможны процессы ПЭ с участием возбужденных синглетных и триплетных состояний молекул А. Әкспериментальные доказательства такого рода процессов с участием триплетных молекул хлорофилла и некоторых производных порфина представлены в $\left[{ }^{24-26}\right]$. Синглет-триплет-триплетный (СТT) перенос может носить как гомогенный, так и гетерогенный характер. Он протекает по схеме:

$$
{ }^{1} D^{*}+{ }^{3} A^{*} \rightarrow{ }^{1} D+{ }^{3} A^{* *} \rightarrow{ }^{1} D+{ }^{3} A^{*}+\text { тепло. }
$$

Теория резонансных взаимодействий не исключает возможности ПЭ на триплетно-возбужденные молекулы А и в том случае, когда излучательный переход в молекулах Д носит запрещенный характер (фосфоресценция). Таким процессом является обнаруженный нами триплеттриплет-триплетный (ТТТ) ПЭ, реализующийся по следующей схеме:

$$
{ }^{3} D^{*}+{ }^{3} A^{*} \rightarrow{ }^{1} D+{ }^{3} A^{* *} \rightarrow{ }^{1} D+{ }^{3} A^{*}+\text { тепло. }
$$

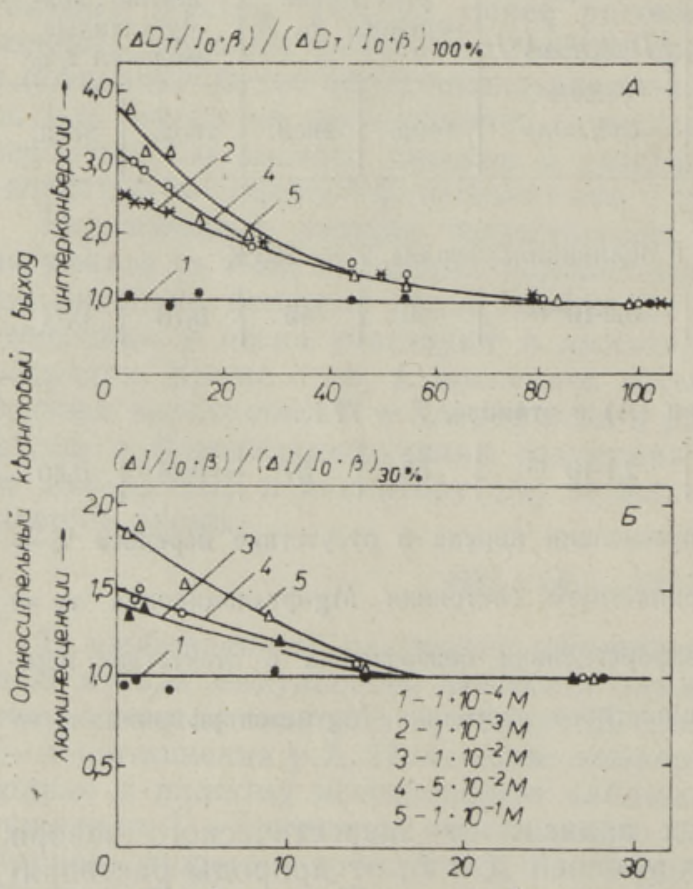

uнтенсивность unлуиьсноео вазбурсяения, \%
Как видно из схем (3) и (4), дополнительного возрастания свечения А в результате ПЭ в этом случае не происходит. Существование СТТ- и ТTТ-переноса прямо и убедительно доказывают наблюдения кинетики затухания свечения молекул Д в присутствии триплетно-возбужденных молекул А, впервые выполненные нами методами кинетической лазерной и импульсной спектроскопии $[24,26]$. Как видно из табл. 2, для

Рис. 3. Зависимость относительного квантового выхода образования триплетных молекул (А) и относительного квантового выхода люминесценции (Б) растворов хлорофилла $a$ в касторовом масле при $T=183 \mathrm{~K}$ от интенсивности импульсного фотовозбуждения. 
исследованных донорно-акцепторных пар наблюдается хорошее соответствие экспериментальных результатов и расчетов по теории Ферстера-Галанина.

В высококонцентрированных растворах хлорофилла $a$ и феофитина $a$ в касторовом масле при $183 \mathrm{~K}$ на установке лампового флеш-фотолиза были выполнены эксперименты, позволившие обнаружить гомогенный СТТ-перенос с синглетно-возбужденных молекул пигмента на его же триплетно-возбужденные молекулы $\left[{ }^{27}\right]$. Как видно из рис. 3 , с повышением концентрации молекул в растворе относительные квантовые выходы интерконверсии и люминесценции возрастают при уменьшении интенсивности возбуждающего импульса. При этом время жизни три-

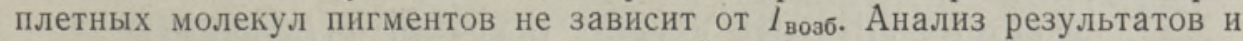
расчеты показали, что главной причиной наблюдаемых эффектов является именно гомогенный СТТ ПЭ. Проведенные эксперименты дают основание полагать, что в фотосинтетическом аппарате растений, где имеет место эффективный ПЭ, при возбуждении мощными световыми потоками процессы такого рода могут играть заметную роль.

\section{ЛИТЕРА Т У Р А}

1. Clayton, R., Molecular Physics in Photosynthesis, Blaisdel Publishing Company, New York, 1965.

2. Robi n s o n, G. W., Brookhaven Symp. Biol., 19, 16-28 (1967).

3. Бо р и сов А. Ю., Год и к В. Н., В кн.: Биофизика фотосннтеза, М., МГУ, 1975, гл. II, с. $124-142$.

4. Гуринович Г. П., Лосев А. П., Зенькевич Э. И., В кн.: Хлорофилл, Минск, «Наука и техника», 1974, с. $74-84$.

5. Л осев А. П., З енькевич.Э. И., Ж. прикладной спектроскопии, 9, вып. 1, $144-154$ (1968).

6. Kelly, A. R., Patterson, L. K., Proc. Roy. Soc., A324, 117-126 (1971).

7. Зенькевич Э. И., Лосев А. П., Гуринович Г. П., Изв. АН СССР, сер. физ., 36, № 5, 979-983 (1972).

8. B e d d a r d, G. S., P or t e r, G., Nature, 260, 366 (1976).

9. Зенькевич Э. И., Сагун Е. И., Лосев А. П., Гуринович Г. П., Оптика и спектроскопия, 49, вып. 5, 896-902 (1980).

10. Gurinovich, G. P., Losev, A. P., Zen'kevich, E. I., Spectrosc. Lett., 11, 493-511 (1978).

11. Craver, F. W., Knox, R. S., Mol. Phys., 22, № 3, 385-402 (1972).

12. Бодуно в Е. Н., Ж. прикладной спектроскопин, 26, вып. 6, 1123-1125 (1977).

13. Förster, Th., Fluoreszenz organischer Verbindungen, Vandenhoeck und Ruprecht, Göttingen, 1951.

14. Га л а н н М. Д., Тр. Физ. ин-та АН СССР, 12, 3-53 (1960).

15. З ен нкев и Ч. И., Л осе в А. П., Изв. АН СССР, сер. физ., 39, № 9, 1845-1850 (1975).

16. З енькевич Э. И., Л осев А. П., Гуринович Г. П., Молекуляр. биол, 9, вып. 4, 516-523 (1975).

17. Зенькевич Э. И., Кочубеев Г. А., Лосев А. П., Гуринович Г. П., Молекуляр. биол., 13, вып. 4, 888-898 (1979).

18. Зенькевич Э. И., Саржевский М. В., Витовцева Т. В., Кочу бе е в Г. А., Молекуляр. биол., 15, вып. 1, 145-151 (1981).

19. Z e n'kevich, E. I. Losev, A. P., Kochubeev, G. A., Gurinovich, G. P., J. Mol. Struct., 45, 423-436 (1978).

20. Breton, I., Math is, P., C. r. Acad. Sci., B271, 1094 (1970).

21. Dutt o n, P. L., Leigh, I. S., S eibert, M., Biochem. Biophys. Res. Communs, 46, № 2, 406-413 (1972).

22. Лосе в А. П., С а г у н Е. И., Ж. прикладной. спектроскопии, 24, вып. 5, 815-820 (1976).

23. Ермолаев В. Л., Бодунов Е. Н., Свешникова Е. Б., Шахвердо в Т. А., В кн.: Безызлучательный перенос энергии электронного возбуждения, Л., «Наука», 1977 , гл. 4, с. 94-164.

24. Гуринович Г. П,, Зенькевич Э. И., Сагун Е. И., Докл. АН БССР, 24, № 4, 315-318 (1980).

25. Гуринович Г. П., Зенькевич Э. И., Сагун Е. И., Изв. АН СССР, сер. физ,, 44, № 4, 693-701 (1980). 
26. Гу у иин ович Г. П̈., З еньке вич Э. И., С агун Е. И., Докл. АН̈ СССР, 257̈, № $1,70-74$ (1981).

27. Зенниевич Э. И., Сагун Е. И., Лосев А. П., Гуринович Г. П., Ж. прикладной спектроскопии, 32, вып. 6, 1047-1055 (1980).

Институт физики

Академии наук Белорусской ССР

E. I. ZENKEVITS, G. P. GURINOVITS, E. I. SAGUN

\title{
ELEKTRONERGASTUSE ENERGIA OLEKANNE KLOROFOLLI JA TA DERIVAATIDE OSAVOTUL
}

On antud ülevaade elektronergastuse energia ülekande vōimalikest mehhanismidest juhul, kui ülekandes osalevad klorofüll ja temaga kaasnevad pigmendid ning mõningad porfüriinide derivaadid, esitatud erinevate ülekandetüüpide seaduspärasuste ja mehhanismide uurimise tulemused ning võrreldud eksperimendiandmeid uuemate teooriate alusel tehtud arvutustega.

\author{
E. I. ZEN'KEVICH, G. P. GURINOVICH, E. I. SAGUN
}

\section{ELECTRONIC EXCITATION ENERGY TRANSFER WITH THE PARTICIPATION OF THE MOLECULES OF CHLOROPHYLL AND ITS DERIVATIVES}

The results of an experimental investigation of the regularities and mechanisms of different types of energy, transfer with the participation of chlorophyll molecules, accompanying pigments and some porphyrin derivatives under different conditions (from molecular solutions up to aggregated complexes), are presented. A comparison of the experimental results and the theoretical calculations according to present-day theories for the known energy transfer types is made. The results obtained may be used for the elucidation of a possible role of the triplet and singlet states in energy migration processes in the photosynthetic apparatus of green plants. 